From the Department of Epidemiology and Cancer Control, St Jude Children's Research Hospital, Memphis, TN; Department of Public Health Sciences, University of Alberta, Edmonton, Alberta, Canada; Department of Pediatrics, University of Minnesota School of Medicine, Minneapolis, MN; Fred Hutchinson Cancer Research Center, Seattle, WA; Department of Pediatrics, Emory University, Atlanta, GA.

Submitted November 18, 2008; accepted November 19, 2008; published online ahead of print at www.jco.org on March 30, 2009.

Support by American Lebanese-Syrian Associated Charities and grant No. U24-CA55727 from the National Cancer Institute.

Authors' disclosures of potential conflicts of interest and author contributions are found at the end of this article.

Corresponding author: Gregory T. Armstrong, MD, MSCE, Department of Epidemiology \& Cancer Control, St Jude Children's Research Hospital, 262 Danny Thomas PI, Memphis, TN 38105; e-mail: greg.armstrong@ stjude.org

(C) 2009 by American Society of Clinical Oncology

0732-183X/09/2714-2328/\$20.00

DOI: $10.1200 / J C O .2008 .21 .1425$

\title{
Late Mortality Among 5-Year Survivors of Childhood Cancer: A Summary From the Childhood Cancer Survivor Study
}

Gregory T. Armstrong, Qi Liu, Yutaka Yasui, Joseph P. Neglia, Wendy Leisenring, Leslie L. Robison, and Ann C. Mertens

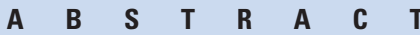

The Childhood Cancer Survivor Study (CCSS) has assembled the largest cohort to date for assessment of late mortality. Vital status and cause of death of all patients eligible for participation in CCSS was determined using the National Death Index and death certificates to characterize the mortality experience of 20,483 survivors, representing 337,334 person-years of observation. A total of 2,821 deaths have occurred as of December 31, 2002. The overall cumulative mortality is $18.1 \%(95 \% \mathrm{Cl}, 17.3$ to 18.9$)$ at 30 years from diagnosis. With time, while all-cause mortality rates have been stable, the pattern of late death is changing. Mortality attributable to recurrence or progression of primary disease is decreasing, with increases in rates of mortality attributable to subsequent neoplasms (standardized mortality ratios [SMR], 15.2; 95\% Cl, 13.9 to 16.6), cardiac death (SMR, 7.0; 95\% Cl, 5.9 to 8.2), and pulmonary death (SMR, 8.8; 95\% Cl, 6.8 to 11.2) largely due to treatment-related causes. In addition, the CCSS has identified specific treatment-related risk factors for late mortality. Radiotherapy (relative risk $[R R], 2.9 ; 95 \% \mathrm{Cl}, 2.1$ to 4.2 ), alkylating agents (RR, 2.2; $95 \% \mathrm{Cl}, 1.6$ to 3.0), and epipodophyllotoxins (RR, 2.3; $95 \% \mathrm{Cl}, 1.2$ to 4.5$)$ increase the risk of death due to subsequent malignancy. Cardiac radiation exposure $(\mathrm{RR}, 3.3 ; 95 \% \mathrm{Cl}, 2.0$ to 5.5) and high dose of anthracycline exposure (RR, 3.1;95\% Cl, 1.6 to 5.8) are associated with late cardiac death. By continued longitudinal follow-up of the cohort and expansion of the cohort to include patients diagnosed between 1987 and 1999, the CCSS will remain a primary resource for assessment of late mortality of survivors of childhood cancers.

\section{J Clin Oncol 27:2328-2338. (C) 2009 by American Society of Clinical Oncology}

\section{INTRODUCTION}

Five-year survival rates for most childhood cancers have improved significantly over the past four decades. In the modern era of cancer treatment, more than $80 \%$ of children diagnosed with a pediatric malignancy will become 5-year survivors of their cancer, due largely to the use of advanced diagnostic modalities, and improvements in surgical and radiation therapy techniques, combination chemotherapy, and supportive care. ${ }^{1,2}$ This dramatic increase in survival has resulted in a new and growing population of long-term survivors of childhood cancer that did not exist just a few decades ago. Currently, it is estimated that one in every 640 young adults between the ages of 20 and 39 is a survivor of pediatric cancer. ${ }^{1}$

Unfortunately, this increased rate of survival does not come without a cost to the survivor. There is significant long-term morbidity and mortality associated with treatment of childhood cancer, the incidence of which continues to increase long after completion of therapy. The Childhood Cancer Survivor Study (CCSS) has assembled the largest cohort to date for assessment of late mortality and morbidity among 5-year survivors of childhood and adolescent cancer. The mortality experience of 20,483 survivors diagnosed between 1970 and 1986, representing 337,334 person-years of observation, including 2,821 deaths, has broadened our understanding of the true risk of death among 5-year survivors relative to background rates in the general population. In addition, cause-specific attribution of death has allowed identification of trends in mortality due to treatment-related causes separately from death due to recurrence or progression of primary disease. As such, these data have allowed identification of key risk factors for long-term treatment related mortality.

Only a limited number of studies exist that explore late mortality in patients treated before 1970. Many of the seminal findings from this earliest era of cancer care have been validated and markedly expanded on by the work of the CCSS on patients 
diagnosed between 1970 and 1986. These early reports established higher death rates in survivors compared to siblings, attribution of death primarily to recurrence of primary malignancy, an increasing risk of nonprimary malignancy related death with increasing time from diagnosis, and early associations of treatment modalities with late death. ${ }^{3-5} \mathrm{Li}$ et al reported $83 \%$ overall survival at 20 years from diagnosis in a population of 1,807 5-year survivors diagnosed between 1950 and $1969 .{ }^{3}$ However, it is noteworthy that before 1970 the treatment exposures of 5-year survivors were substantially different as most treatment regimens were limited to surgical resection with or without radiotherapy, with minimal exposure to chemotherapeutic agents. ${ }^{5}$ As a result, certain primary diagnoses were associated with very high rates of late death, as in the case of acute lymphoblastic leukemia (ALL) where, before CNS-directed therapy, CNS relapse ultimately lead to an increase in late mortality rates, higher than that observed in CCSS. Ten-year survival probabilities were lower than $50 \%$ for ALL and only 65\% for Hodgkin's lymphoma in this earlier era, as opposed to those with Wilms tumor, low-stage neuroblastoma, or retinoblastoma who responded well to surgery and radiotherapy. ${ }^{3}$ Regarding deaths attributable to treatment-related causes, Hawkins et al, in a population-based investigation of late mortality in 4,082 British patients diagnosed before 1971, first documented a five-fold increase in cardiovascular death largely due to early myocardial infarction and cerebrovascular accidents. ${ }^{4}$ In addition, they reported that more than $25 \%$ of 5-year survivors of Hodgkin's disease, ependymoma, medulloblastoma, and Ewing's sarcoma died of recurrent tumor, with a strong propensity for late relapse within these diagnostic groups. Overall, they observed three times the number of deaths expected due to non-neoplastic causes. Many questions remained, however, at the conclusion of these studies, largely regarding the emerging use of chemotherapy and increasing intensity of therapy in the late 1960s and early 1970s and its effect on late mortality. It was even hypothesized that late mortality may become more pronounced in future cohorts of survivors receiving these modern primary therapies, secondary to improved salvage rates. ${ }^{5}$

\section{SPECIFIC METHODS FOR MORTALITY ASSESSMENT}

\section{Ascertainment of Cause of Death}

Names of all patients eligible for participation in the CCSS were included in a search for deaths using the National Death Index (NDI) from 1979 to 2002. The NDI is an index of death record information compiled from individual state vital statistics offices through contractual agreements with the National Center for Health Statistics. The NDI also has available the underlying and multiple causes of death for deceased subjects using the International Classification of Disease (ICD) ninth revision. The underlying cause of death identifies the initiating cause of death, and the rules for selecting the underlying cause of death are standardized. In the US, death statistics are based on the underlying cause of death, and are therefore a useful means of standardizing classification of deaths in studies such as the CCSS.

For deaths that predated the NDI (ie, 1975 to 1978), death certificates from states where deaths occurred were requested. Cause of death was determined from information provided by the NDI in addition to the information provided on death certificates. Based on this information, and augmented by our knowledge of the original cancer diagnosis as well as telephone interviews with parents of de- ceased CCSS participants, the original CCSS mortality manuscript published in $2001^{6}$ classified all deaths as either (1) a direct consequence of the original cancer diagnosis, including recurrence or progression of the primary disease, or death due to acute toxicity while on therapy for the original diagnosis; (2) cancer treatment-related death, defined as a death where nonacute treatment effects were considered to be the major contributing factor to death (eg, subsequent malignant neoplasm, cardiac, or pulmonary toxicity); or (3) non-treatmentrelated causes, such as deaths due to other conditions or external causes. The most recent mortality update from the CCSS, however, published in 2008, used a more restricted classification schema attributing death to either: (1) recurrence (or progression) of primary disease, (2) external causes, or (3) nonrecurrence, nonexternal causes. ${ }^{7}$ This review reports vital status as of December 31, 2002, congruent with the most recent report from CCSS.

\section{Analytic Methods}

Evaluation of late mortality for all CCSS studies began 5 years from the time of diagnosis and continued until the date of death or the date of censoring, December 31, 2002, if alive. Rates of deaths per 1,000 person-years were calculated for 5-year time intervals after cohort entry. Standardized mortality ratios (SMRs) were also used to quantify the relative rate of mortality in this cohort, relative to the age-, calendar year-, and sex-matched United States' general population. Details of methods used for calculation of mortality rates, SMRs, and survival functions have been previously reported. ${ }^{6,8}$ In addition to calculation of all-cause SMRs, cause-specific SMRs were calculated by excluding deaths attributable to recurrence or progression of the primary malignancy. Specific causes of death were grouped into six categories: secondary or subsequent cancer (ICD 140-239), cardiac (ICD 390- 398, 402, 404, 410- 429), pulmonary (ICD 460-519), external causes (ie, accidents, suicides, poisonings; ICD 800-999) and other causes (all other ICD codes). Multivariable Poisson regression was used to assess the impact of specific treatment modalities on the risk of mortality not attributable to recurrence or progression of primary disease, while adjusting for factors including sex, age at diagnosis, and time since diagnosis.

\section{OVERALL MORTALITY}

For decades, clinicians and patients alike have used 5-year survival from the time of diagnosis as a generalized benchmark for cure (5-year event-free survival) and for overall assessment of therapeutic regimens (5-year overall survival). However, the risk of cancer and cancer therapy-related death extends well beyond this arbitrary 5 -year point. Unfortunately, most therapeutic protocols were not designed to monitor patients far beyond the time point for assessing clinical efficacy (eg, typically $<5$ to 7 years from diagnosis). Moreover, most pediatric oncology programs are not structured to systematically follow patients as long-term survivors into adulthood. For these reasons, assessment of late mortality is generally dependent on epidemiologic studies to inform us of the existent risks and risk factors for late occurring death. The CCSS, as a retrospective cohort study that continues to monitor the cohort through longitudinal assessment, serves as an ideal platform to estimate the risk of late mortality in a wellcharacterized population.

The most recent report of late mortality from the CCSS included a total of 2,821 deaths that have occurred among the 20,483 eligible 
5-year survivors. ${ }^{7}$ With increasing time from primary cancer diagnosis, one would hope that the annual mortality rate of childhood cancer survivors may eventually return to a level that mirrors that of the background population in the United States. Unfortunately, this is not the case. When the all-cause mortality experience of 5-year survivors of childhood cancer is compared to the age-adjusted expected survival rates for the United States population (Fig 1A), at no point in the first 30 years after diagnosis is this estimate of survival for those with childhood cancer similar to the background population. The mortality rates from 5 to 9,10 to 19,20 to 29 , and $30+$ years from diagnosis are $13.57,6.00,6.52$, and 14.22 deaths per 1,000 person-years, respectively, compared to expected rates of $0.66,1.03,1.44$, and 2.07 deaths per 1,000 person-years for the United States population. In addition, the overall (cumulative) mortality increases significantly over time: $6.5 \%$ at 10 years (95\% CI, 6.2 to 6.9$), 11.9 \%$ at 20 years $(95 \%$ CI, 11.5 to 12.4 ) increasing to $18.1 \%$ at 30 years from diagnosis (95\% CI, 17.3 to 18.9$)$. Considering that the risk of death due to primary malignancy decreases with increasing time from diagnosis, these elevated rates of

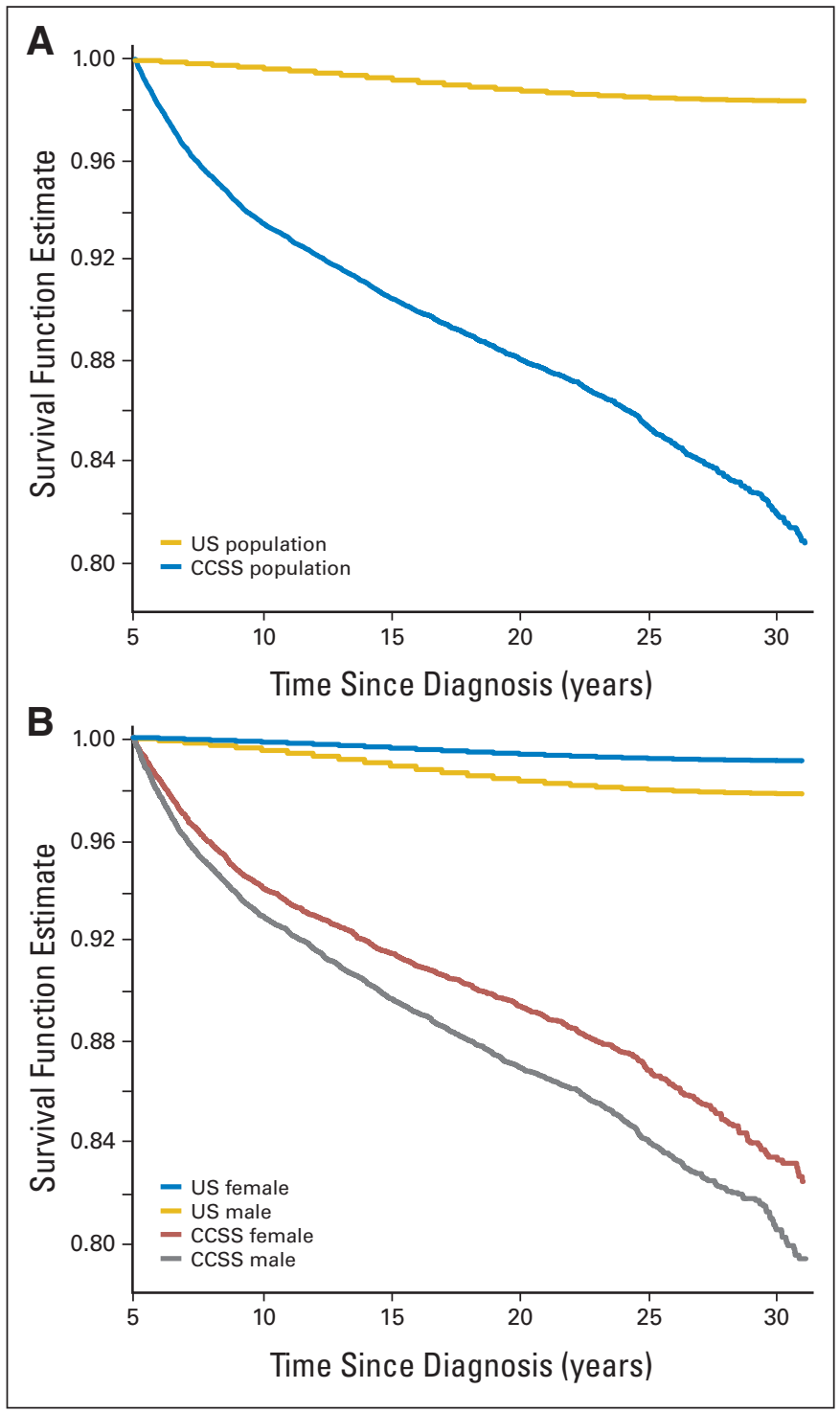

Fig 1. (A) All-cause mortality (survival function estimate): entire cohort. (B) All-cause mortality (survival function estimate) by sex. mortality occurring 20 and 30 years after diagnosis suggest other causes for late mortality become increasingly important with time.

\section{TEMPORAL CHANGES IN CAUSE-SPECIFIC MORTALITY}

In the original report identifying deaths through December 31, 1996, recurrence, or progression of primary disease, was the cause of death in $67.4 \%$ of patients with nonrecurrence, nonexternal causes of death reported for $27.5 \%$, and $5.1 \%$ of deaths attributable to external causes. With only 6 years of additional follow-up, however, these proportions changed dramatically to $58.0 \%, 34.7 \%$, and $7.3 \%$, respectively (Table 1). This change, with ongoing follow-up, in the proportion of deaths attributable to recurrence/progression compared to nonrecurrence, nonexternal death is confirmed by Figure 2 . While the mortality rate for death due to the original malignancy begins to plateau beyond 20 years, the rate of death from all nonrecurrence, nonexternal causes increases. Between 15 and 30 years, the cumulative mortality attributable to primary disease increased from $6.3 \%$ to only $7.8 \%$, while the cumulative mortality due to nonrecurrent, nonexternal causes increased from $2.0 \%$ to $7.0 \%$ over the same period. This sharp increase in late-mortality attributable to nonrecurrent, nonexternal causes exceeds what would be expected in the United States population and is largely due to an increase in treatment-related mortality as this population ages.

Assessment of mortality rates within 5-year time blocks from diagnosis (Table 2) demonstrates that the death rate from nonrecurrence, nonexternal causes eventually exceeds, with time, death from primary disease. By 15 years from diagnosis, the mortality rate from nonrecurrent and nonexternal causes exceed the rate from primary disease. By 20 years, death attributable to subsequent malignant neoplasm exceeds death from primary disease and at 30 years, recurrence of primary disease is the least likely cause of late mortality. These findings demonstrate that the pattern of late mortality changes over time and that death from sequelae of treatment received 20 to 30 years earlier is a considerable threat to this population now in young adulthood. It is essential, therefore, to assess which populations are at greatest risk and what treatment modalities lead to this increased risk for late death.

\section{POPULATIONS AT RISK}

The CCSS population includes most major pediatric oncology diagnostic groups (ie, leukemia, CNS tumors, Hodgkin's disease, non-Hodgkin's lymphoma, malignant renal tumors [Wilms], neuroblastoma, soft tissue sarcoma, and bone tumors), diagnosed across a broad time interval (1970 to 1986), from multiple institutions, receiving a wide array of therapies and more than 20 years of mean followup. Performing a mortality analysis in such a large, heterogeneous population as the CCSS provides opportunity to identify specific subpopulations that may be at higher risk for late mortality. Furthermore, standardization of mortality data (Table 3 ) to the background rates of death in the United States population allows not only a relative assessment of the differences in rate of death compared to this established background rate, but also provides a meaningful way to compare the mortality experience of two populations within the CCSS cohort.

It is not surprising that long-term survivors have higher rates of late mortality in the 5- to 9-year period (SMR, 20.7; 95\% CI, 19.6 


\begin{tabular}{|c|c|c|c|c|c|c|c|}
\hline \multirow[b]{3}{*}{ Specific Cause of Death } & \multirow[b]{3}{*}{ ICD-9 Code } & \multicolumn{6}{|c|}{$\%$} \\
\hline & & \multicolumn{2}{|c|}{ Total Deaths } & \multicolumn{2}{|c|}{ Male } & \multicolumn{2}{|c|}{ Female } \\
\hline & & No. & $\%$ & No. & $\%$ & No. & $\%$ \\
\hline Total known causes in each column & & 2,534 & & 1,511 & & 1,023 & \\
\hline Recurrence/progressive disease & & 1,469 & 58.0 & 882 & 58.4 & 587 & 57.4 \\
\hline Medical causes of death & & 879 & 34.7 & 477 & 31.6 & 402 & 39.3 \\
\hline Infectious and parasitic diseases & 001-139 & 48 & 1.9 & 23 & 1.5 & 25 & 2.4 \\
\hline Subsequent neoplasm & $140-239$ & 470 & 18.5 & 242 & 16.0 & 228 & 22.3 \\
\hline Lip, oral cavity, pharynx & $140-149$ & 7 & 0.3 & 4 & 0.3 & 3 & 0.3 \\
\hline Digestive organs and peritoneum & 150-159 & 38 & 1.5 & 16 & 1.1 & 22 & 2.2 \\
\hline Respiratory and intrathoracic organs & $160-165$ & 23 & 0.9 & 10 & 0.7 & 13 & 1.3 \\
\hline Bone, connective tissue, skin & $170-173$ & 86 & 3.4 & 47 & 3.1 & 39 & 3.8 \\
\hline Breast & $174-175$ & 38 & 1.5 & 0 & 0.0 & 38 & 3.7 \\
\hline Genitourinary organs & 179-189 & 23 & 0.9 & 8 & 0.5 & 15 & 1.5 \\
\hline Brain and nervous system & 191-192 & 73 & 2.9 & 52 & 3.4 & 21 & 2.1 \\
\hline Lymphatic and hematopoietic & $200-208$ & 129 & 5.1 & 75 & 5.0 & 54 & 5.3 \\
\hline Other subsequent cancer & & 53 & 2.1 & 30 & 2.0 & 23 & 2.2 \\
\hline Endocrine, nutritional, and metabolic diseases and immunity disorders & $240-279$ & 14 & 0.6 & 7 & 0.5 & 7 & 0.7 \\
\hline Disease of blood and blood-forming organs & 280-289 & 9 & 0.4 & 5 & 0.3 & 4 & 0.4 \\
\hline Mental disorders & 290-319 & 7 & 0.3 & 5 & 0.3 & 2 & 0.2 \\
\hline Diseases of the nervous system and sense organs & 320-389 & 21 & 0.8 & 9 & 0.6 & 12 & 1.2 \\
\hline Diseases of the circulatory system & $390-459$ & 176 & 6.9 & 110 & 7.3 & 66 & 6.5 \\
\hline Ischemic heart disease & $410-414$ & 44 & 1.7 & 32 & 2.1 & 12 & 1.2 \\
\hline Cardiomyopathy & 425 & 46 & 1.8 & 28 & 1.9 & 18 & 1.8 \\
\hline Heart failure & 428 & 6 & 0.2 & 4 & 0.3 & 2 & 0.2 \\
\hline Cerebrovascular diseases & 430-438 & 19 & 0.7 & 11 & 0.7 & 8 & 0.8 \\
\hline Other cardiac & & 61 & 2.4 & 35 & 2.3 & 26 & 2.5 \\
\hline Diseases of the respiratory system & $460-519$ & 67 & 2.6 & 39 & 2.6 & 28 & 2.7 \\
\hline Pneumonia & $480-486$ & 24 & 0.9 & 14 & 0.9 & 10 & 1.0 \\
\hline Pulmonary fibrosis & 515 & 13 & 0.5 & 8 & 0.5 & 5 & 0.5 \\
\hline Other pulmonary & & 30 & 1.2 & 17 & 1.1 & 13 & 1.3 \\
\hline Diseases of the digestive system & $520-579$ & 28 & 1.1 & 15 & 1.0 & 13 & 1.3 \\
\hline Diseases of the genitourinary system & $580-629$ & 8 & 0.3 & 5 & 0.3 & 3 & 0.3 \\
\hline Complications of the puerperium & $670-676$ & 1 & 0.0 & 0 & 0.0 & 1 & 0.1 \\
\hline Diseases of the musculoskeletal system and connective tissue & $710-739$ & 8 & 0.3 & 3 & 0.2 & 5 & 0.5 \\
\hline Congenital anomalies & $740-759$ & 8 & 0.3 & 4 & 0.3 & 4 & 0.4 \\
\hline Symptoms, signs, and ill-defined conditions & 780-799 & 14 & 0.6 & 10 & 0.7 & 4 & 0.4 \\
\hline External causes of injury and poisoning & E800-E999 & 186 & 7.3 & 152 & 10.1 & 34 & 3.3 \\
\hline Motor vehicle accidents & E810-E825 & 80 & 3.2 & 67 & 4.4 & 13 & 1.3 \\
\hline Other accidents & E826-E929 & 44 & 1.7 & 37 & 2.4 & 7 & 0.7 \\
\hline Suicide & E950-E959 & 39 & 1.5 & 35 & 2.3 & 4 & 0.4 \\
\hline Homicide & E960-E978 & 17 & 0.7 & 10 & 0.7 & 7 & 0.7 \\
\hline Other injury & E980-E999 & 6 & 0.2 & 3 & 0.2 & 3 & 0.2 \\
\hline Unknown cause of death & & 287 & & 175 & & 112 & \\
\hline
\end{tabular}

NOTE. Bold font indicates four major categories of death.

Abbreviation: ICD-9, International Classification of Disease, 9th revision.

to 21.8) from diagnosis with decreasing rates of death with ongoing time from diagnosis (Table 3). This corresponds with increased rates of death due to recurrence or progression of primary disease seen during this time period. In addition, young patients (those diagnosed and treated in the first 4 years of life) have higher SMRs (SMR, 9.1; 95\% CI, 8.5 to 9.8) than those who were older at diagnosis. This may be driven by the fact that certain diagnostic groups, such as ALL and CNS tumors, the two most commonly diagnosed pediatric malignancies, young age is itself a poor prognostic factor (Fig 3). ${ }^{9}$ In addition, important therapeutic modalities are often limited in young patients, such as the use of CNS directed radiotherapy, in an attempt to prevent long-term injury.
Avoidance of such therapies may also lower the risk of longterm survival. ${ }^{10}$

Certain primary diagnoses carry greater risk of poor long-term survival. As a group, CNS tumors have the highest SMR of any population (SMR, 12.9; 95\% CI, 11.8 to 14.0 ) largely driven by the high long-term risk for death for patients with medulloblastoma (SMR, 17.7; 95\% CI, 14.8 to 21.1 ). Thus, even after surviving to the 5 -year time point, subjects with medulloblastoma or PNET had an almost 18 -fold increased risk of death relative to a comparable ageand sex-matched United States population. It is unclear whether this high rate is attributable to the use of CNS directed radiotherapy without adjuvant chemotherapy in this era (1970 to 1986) or to 


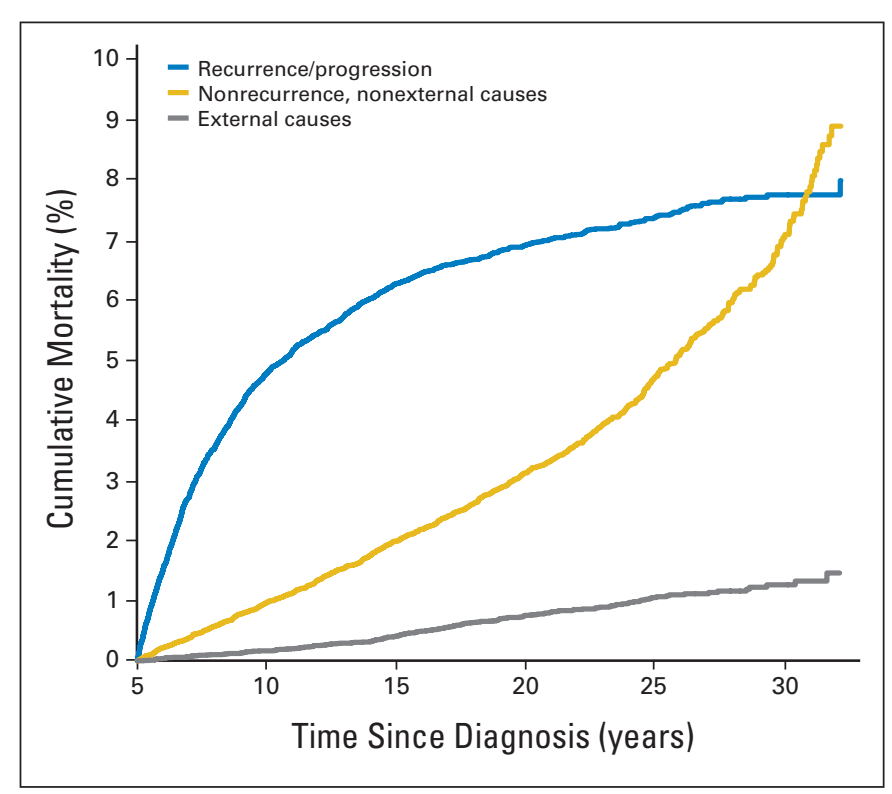

Fig 2. Cumulative cause-specific mortality.

inadequate salvage therapies for relapsed patients. In addition, long-term survivors of acute myelogenous leukemia (SMR, 11.5; 95\% CI, 9.1 to 14.3 ) and Ewing's sarcoma (SMR, 13.3; 95\% CI, 11.2 to 15.8 ) have increased SMRs relative to other diagnostic groups. At the opposite extreme, patients with renal tumors (predominately Wilms' tumor) and neuroblastoma had the best overall survival with cumulative incidence of death of $7.3 \%$ and $8.6 \%$, respectively, at 30 years from diagnosis (Fig 4).

Finally, while males in the CCSS cohort have a greater absolute risk for death than females (Fig 1B), when standardized to the background rate of death in the United States population, by sex, it is females who have a higher SMR (13.2; 95\% CI, 12.5 to 14.0) compared to males (SMR, 6.7; 95\% CI, 6.4 to 7.0). Young males in the general population are known to have a higher rate of death due to accidents and injuries; therefore, the use of these data as the denominator for standardization partially explains the lower SMR in males. However, female survivors are at significantly greater risk of second cancers, specifically breast cancer, than their male counterparts which likely increases the gap in the SMRs between the sexes.

\section{CAUSE-SPECIFIC MORTALITY}

\section{Death Due to Recurrence}

The overall mortality rate of death due to recurrence or progression of the primary malignancy is 4.4/1,000 person-years (annual risk of death, $0.44 \% /$ year). Males have a small, but statistically increased risk of recurring and then dying from their recurrence as compared to females (annual mortality rate $0.48 v 0.38 ; P<.05$ ). Death due to recurrence varied across diagnostic groups with medulloblastoma (1.14\%/year), other CNS tumors, largely consisting of ependymomas (0.95\%/year) and Ewing's sarcoma (0.95\%/year) having the highest annual rate of late death due to recurrence while non-Hodgkin's lymphoma (0.15\%/year) and neuroblastoma (0.18\%/year) had the lowest rates. In addition, patients diagnosed between 1970 and 1973 (earliest treatment era in this cohort) had the highest rate of death from recurrence $(0.48 \%$ /year) as well as those who were diagnosed in late childhood. Participants diagnosed between the ages of 15 to 20 years $(0.59 \% /$ year) were at increased risk compared to all other age groups while the youngest group, age 0 to 4 years had the lowest risk for death due to recurrence $(0.33 \%$ /year $)$.

\section{Death Due to Nonrecurrent, Nonexternal Causes}

Across all categories (ie, subsequent malignancy, cardiac, pulmonary, and other medical causes of death), survivors of childhood cancer are at increased risk of death compared to age-, calendar year-, and sex-specific rates in the United States population (Table 4). Survivors were 15.2 times more likely to die of a subsequent cancer, 7 times more likely to die from cardiac-related events, 8.8 times more likely to die of a pulmonary event, and 2.6 times more likely to die from other medical causes. There was no difference in death from external causes (SMR, 0.9; 95\% CI, 0.8 to 1.1). These elevated rates draw important attention to the fact that therapy essential for cure of primary malignancies may well have long-term consequences many years after the risk of recurrence of a primary tumor has past. Such knowledge should not only be communicated to patients and their families at the time of primary diagnosis during the discussion of the risks and benefits of therapy, but also should be used to guide current care of long-term survivors by specifically targeting groups at high risk for late mortality. It is essential, therefore, to better understand who is at risk for these treatment-specific causes of death.

\begin{tabular}{|c|c|c|c|c|c|c|c|c|c|c|c|c|c|c|}
\hline \multirow{2}{*}{$\begin{array}{l}\text { Time From } \\
\text { Diagnosis (years) }\end{array}$} & \multicolumn{2}{|c|}{ Recurrence } & \multicolumn{2}{|c|}{$\begin{array}{l}\text { Nonrecurrence, } \\
\text { Nonexternal } \\
\text { Causes }\end{array}$} & \multicolumn{2}{|c|}{ SMN } & \multicolumn{2}{|c|}{ Cardiac } & \multicolumn{2}{|c|}{ Pulmonary } & \multicolumn{2}{|c|}{ Other* } & \multicolumn{2}{|c|}{ External } \\
\hline & Rate & $95 \% \mathrm{Cl}$ & Rate & $95 \% \mathrm{Cl}$ & Rate & $95 \% \mathrm{Cl}$ & Rate & $95 \% \mathrm{Cl}$ & Rate & $95 \% \mathrm{Cl}$ & Rate & $95 \% \mathrm{Cl}$ & Rate & $95 \% \mathrm{Cl}$ \\
\hline $5-9$ & 9.9 & 9.3 to 10.6 & 2.0 & 1.7 to 2.3 & 1.3 & 1.1 to 1.6 & 0.2 & 0.1 to 0.3 & 0.1 & 0.1 to 0.2 & 0.3 & 0.2 to 0.4 & 0.3 & 0.2 to 0.5 \\
\hline $10-14$ & 3.3 & 2.9 to 3.7 & 2.2 & 2.0 to 2.6 & 1.2 & 1.0 to 1.4 & 0.3 & 0.2 to 0.4 & 0.2 & 0.1 to 0.3 & 0.6 & 0.4 to 0.7 & 0.5 & 0.4 to 0.7 \\
\hline $15-19$ & 1.5 & 1.2 to 1.8 & 2.5 & 2.2 to 2.9 & 1.3 & 1.0 to 1.5 & 0.5 & 0.4 to 0.7 & 0.2 & 0.1 to 0.3 & 0.5 & 0.4 to 0.7 & 0.8 & 0.6 to 1.0 \\
\hline $20-24$ & 1.1 & 0.8 to 1.4 & 3.4 & 2.9 to 4.0 & 1.7 & 1.3 to 2.1 & 0.8 & 0.5 to 1.1 & 0.2 & 0.1 to 0.3 & 0.8 & 0.6 to 1.2 & 0.6 & 0.4 to 0.9 \\
\hline $25-29$ & 1.0 & 0.6 to 1.6 & 5.2 & 4.2 to 6.4 & 2.3 & 1.7 to 3.1 & 0.8 & 0.5 to 1.4 & 0.5 & 0.2 to 0.9 & 1.6 & 1.1 to 2.3 & 0.5 & 0.2 to 0.9 \\
\hline 30-34 & 0.5 & 0.0 to 2.6 & 10.1 & 6.3 to 15.3 & 4.6 & 2.2 to 8.4 & 1.4 & 0.3 to 4.0 & 0.9 & 0.1 to 3.3 & 3.2 & 1.3 to 6.6 & 0.9 & 0.1 to 3.3 \\
\hline
\end{tabular}

Abbreviation: SMN, subsequent malignant neoplasm

*Other causes include deaths not due to recurrence, subsequent malignancy, cardiac, pulmonary, or external causes. 


\begin{tabular}{|c|c|c|c|c|}
\hline \multirow[b]{2}{*}{ Parameter } & \multicolumn{2}{|c|}{ No. of Patients } & \multirow[b]{2}{*}{ SMR* $^{*}$} & \multirow[b]{2}{*}{$95 \% \mathrm{Cl}$} \\
\hline & Alive & Dead & & \\
\hline All patients & 17,662 & 2,821 & 8.4 & 8.0 to 8.7 \\
\hline \multicolumn{5}{|l|}{ Sex } \\
\hline Male & 9,636 & 1,686 & 6.7 & 6.4 to 7.0 \\
\hline Female & 8,026 & 1,135 & 13.2 & 12.5 to 14.0 \\
\hline \multicolumn{5}{|l|}{ Age at diagnosis, years } \\
\hline $0-4$ & 7,361 & 820 & 9.1 & 8.5 to 9.8 \\
\hline $5-9$ & 3,984 & 616 & 8.4 & 7.7 to 9.1 \\
\hline $10-14$ & 3,475 & 667 & 7.9 & 7.3 to 8.5 \\
\hline $15-20$ & 2,842 & 718 & 7.9 & 7.4 to 8.5 \\
\hline \multicolumn{5}{|l|}{ Years of diagnosis } \\
\hline 1970-1973 & 2,267 & 664 & 8.2 & 7.6 to 8.9 \\
\hline $1974-1977$ & 3,562 & 735 & 8.0 & 7.4 to 8.6 \\
\hline 1978-1981 & 4,693 & 671 & 7.9 & 7.3 to 8.5 \\
\hline $1982-1986$ & 7,140 & 751 & 11.1 & 10.4 to 12.0 \\
\hline \multicolumn{5}{|l|}{ Survival after diagnosis, years } \\
\hline $5-9$ & - & 1,336 & 20.7 & 19.6 to 21.8 \\
\hline $10-14$ & - & 611 & 7.2 & 6.6 to 7.7 \\
\hline $15-19$ & - & 431 & 4.7 & 4.2 to 5.1 \\
\hline $20-24$ & - & 268 & 4.3 & 3.8 to 4.9 \\
\hline $25-29$ & - & 144 & 5.0 & 4.2 to 5.9 \\
\hline $30-34$ & - & 31 & 6.9 & 4.7 to 9.8 \\
\hline \multicolumn{5}{|l|}{ Diagnosis } \\
\hline Leukemia & 5,482 & 913 & 10.0 & 9.4 to 10.7 \\
\hline Acute lymphoblastic & 5,030 & 730 & 9.5 & 8.8 to 10.2 \\
\hline Acute myeloid & 421 & 80 & 11.5 & 9.1 to 14.3 \\
\hline Other & 391 & 103 & 14.7 & 12.0 to 17.8 \\
\hline CNS tumors & 2,275 & 546 & 12.9 & 11.8 to 14.0 \\
\hline Astrocytomas & 1,489 & 318 & 11.3 & 10.1 to 12.6 \\
\hline Medulloblastoma, PNET & 424 & 128 & 17.7 & 14.8 to 21.1 \\
\hline Other CNS malignancy & 362 & 100 & 14.1 & 11.5 to 17.1 \\
\hline Hodgkin's disease & 2,207 & 510 & 7.8 & 7.1 to 8.5 \\
\hline Non-Hodgkin's lymphoma & 1,381 & 143 & 4.4 & 3.7 to 5.2 \\
\hline Kidney tumors & 1,638 & 97 & 4.6 & 3.8 to 5.6 \\
\hline Neuroblastoma & 1,274 & 84 & 5.6 & 4.4 to 6.9 \\
\hline Soft tissue sarcoma & 1,594 & 244 & 7.1 & 6.2 to 8.1 \\
\hline Bone tumors & 1,451 & 284 & 7.8 & 7.0 to 8.8 \\
\hline Ewings sarcoma & 432 & 136 & 13.3 & 11.2 to 15.8 \\
\hline Osteosarcoma & 930 & 138 & 5.9 & 4.9 to 6.9 \\
\hline Other bone tumors & 89 & 10 & 4.1 & 2.0 to 7.5 \\
\hline
\end{tabular}

As previously mentioned, females have higher rates than males for all causes of death (SMR $13.2 v 6.7 ; P<.001)$, as well as higher rates of death from subsequent malignancy (SMR $16.4 v 14.2 ; P=.10$ ), cardiac death (SMR $8.9 \vee 6.2 ; P=.04)$, and death from other causes (SMR $3.8 v 2.1 ; P<.001)$. This increased rate of long-term complications in females is not surprising as it had been demonstrated that there is an increased propensity for poor long-term outcomes among females across several major outcomes. ${ }^{11}$ In addition to their increased risk for breast cancer after exposure to chest wall radiation, ${ }^{12,13} \mathrm{fe}$ males have disproportionate rates of poor cardiac outcomes after exposure to anthracycline chemotherapy, ${ }^{14,15}$ and higher rates of obesity after exposure to CNS directed radiotherapy, ${ }^{16-18}$ both of which may increase the rate of cardiac-related death.

SMRs were also evaluated based on primary diagnosis. Patients diagnosed originally with medulloblastoma were at highest risk of death due to a subsequent malignancy (SMR, 23.4; 95\% CI, 12.4 to 40.0). These patients generally received craniospinal radiation, and in this era, few patients received chemotherapy. This radiation pattern placed these patients at increased risk of development of subsequent neoplasms, not only in the CNS, which can be rapidly fatal, but for an increased number of soft-tissue sarcomas. Patients treated for Hodgkin's disease (SMR, 20.0; 95\% CI, 16.9 to 23.5) and Ewing's sarcoma (SMR, 20.0; 95\% CI, 12.0 to 31.3) also had very high SMRs for death due to second malignancy relative to other populations. Patients treated for osteosarcoma had the lowest SMR $(8.1 ; 95 \%$ CI, 4.9 to 12.4 ) perhaps because of the limited exposure to radiotherapy in this population.

Standardized rates for cardiac-related deaths were most elevated for survivors of renal tumors (SMR, 12.7; 95\% CI, 6.3 to 22.8) and Hodgkin's disease (SMR, 11.9; 95\% CI, 9.1 to 15.3 ), two populations 


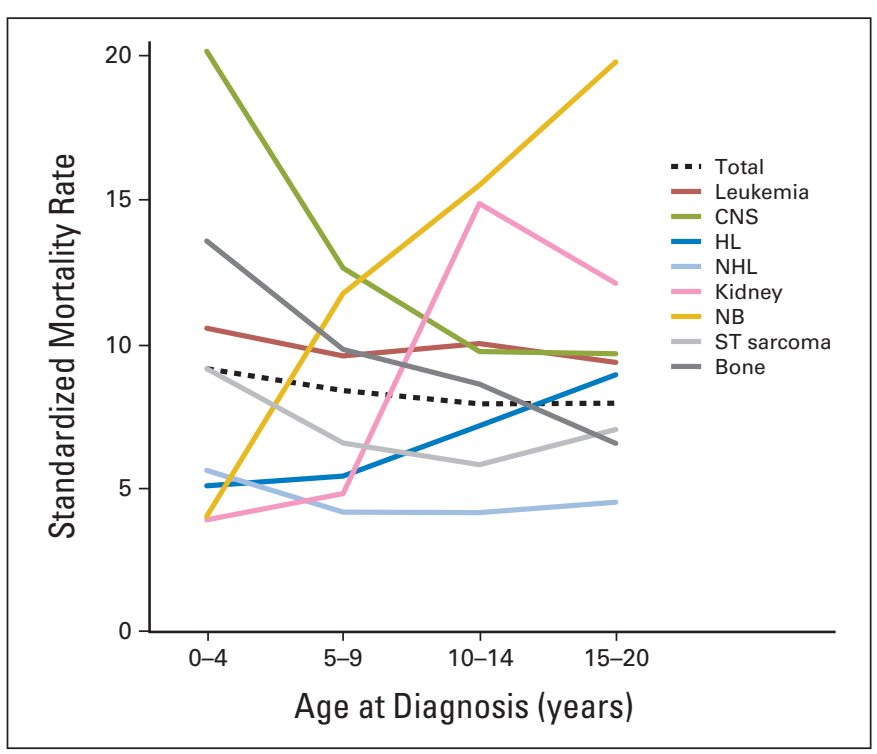

Fig 3. Standardized mortality rates among 5 -year survivors by age at diagnosis for all major childhood cancer diagnoses. HL, Hodgkin's lymphoma; NHL, non-Hodgkin's lymphoma; NB, neuroblastoma; ST, soft tissue.

in which both anthracycline chemotherapy and chest/pulmonary radiotherapy, with its subsequent exposure to the heart were routinely used. Survivors of acute myeloid leukemia (SMR, 24.9; 95\% CI, 6.7 to 63.8) and neuroblastoma (SMR, 11.4; 95\% CI, 3.1 to 29.3 ) were at highest risk for pulmonary death. No statistically significantly elevated rates were seen due to external causes including motor vehicle accidents (SMR, 1.0; 95\% CI, 0.8 to 1.3), other accidents (SMR, 1.3; 95\% CI, 1.0 to 1.8 ), and suicide (SMR, $1.0 ; 95 \% \mathrm{CI}, 0.7$ to 1.4 ).

\section{TREATMENT-RELATED RISK FACTORS FOR LATE MORTALITY}

The large size of the cohort and the detailed medical abstraction used to obtain treatment information affords CCSS the opportunity to investigate treatment-related risk factors for death while controlling for the effects of other known associations with death including: sex, time from diagnosis, and age at diagnosis (Table 5). For each cause of death the relative risk decreases with time from diagnosis. Relative risk was higher for females than males for death due to subsequent malignancy (RR, 1.4; 95\% CI, 1.1 to 1.8 ) and other deaths (RR, 1.9; 95\% CI, 1.5 to 2.5$)$.

Higher rates of death due to subsequent malignancy were seen in patients diagnosed between 0 and 4 years, those who received any radiotherapy exposure, and those who received alkylator or the highest dose level of epipodophyllotoxin exposure. Cardiac radiation and higher doses of anthracyline exposure, both previously established risk factors for cardiac death, were associated with cardiac related death. Finally, in addition to being female, exposure to radiotherapy was associated with death from other causes.

\section{COMPARISON OF CCSS WITH OTHER STUDIES}

Several studies, in addition to the CCSS, have analyzed late mortality in the modern era of cancer treatment, beyond 1970. Robertson et al ${ }^{19}$ followed their assessment of the British population diagnosed before

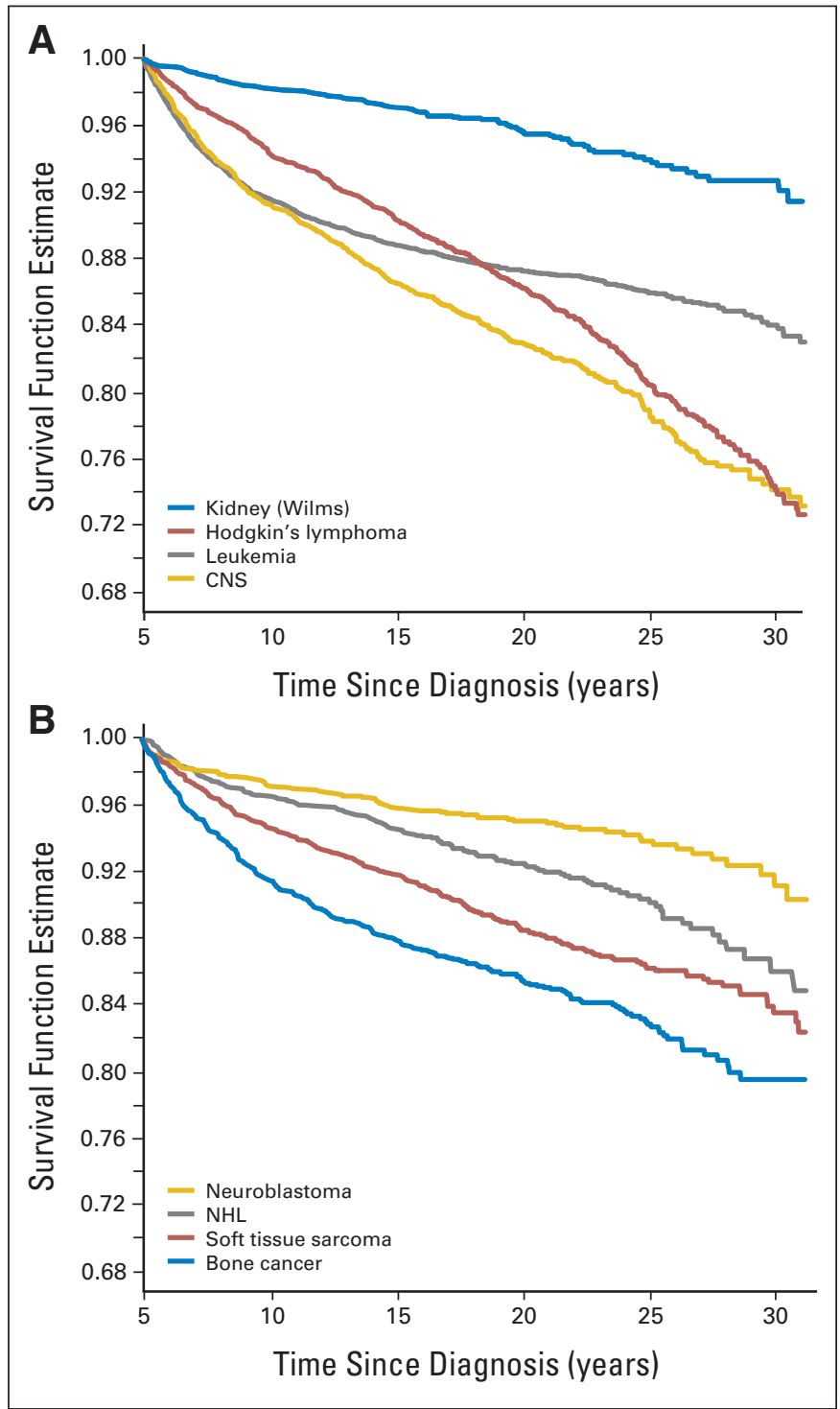

Fig 4. (A and B) All-cause mortality, survival by original cancer diagnosis in the Childhood Cancer Survivor Study. CNS, central nervous system; NHL, nonHodgkin's lymphoma.

1971 with an analysis of 5-year survivors diagnosed between 1971 and 1985. While all childhood cancer diagnoses were eligible, this population was limited to those younger than 15 years of age at diagnosis. Like the CCSS, they reported an increase in non-neoplastic death over time (ie, nonrecurrence and nonsubsequent neoplasm) with an observed to expected ratio of 4 . The proportion of deaths due to causes other than recurrent tumor increased from $23 \%$ during the 5- to 9-year time period from diagnosis to $53 \%$ in the 15 - to 19 -year time period. Perhaps the most important contribution of this publication, ${ }^{19}$ however, is in its comparison to patients diagnosed before 1970. First, initial 5-year survival improved dramatically between theses two cohorts $(25.9 \% \vee 50.4 \%)$; an improvement that changes entirely the make-up of the subsequent surviving population. As a result, there was a reduction in death from recurrence $(11.5 \% v 8.3 \%)$ and a slight increase in death from treatment related causes $(0.8 \% v 1.9 \%)$, perhaps suggesting that improvement in 5 -year survival was also resulting 


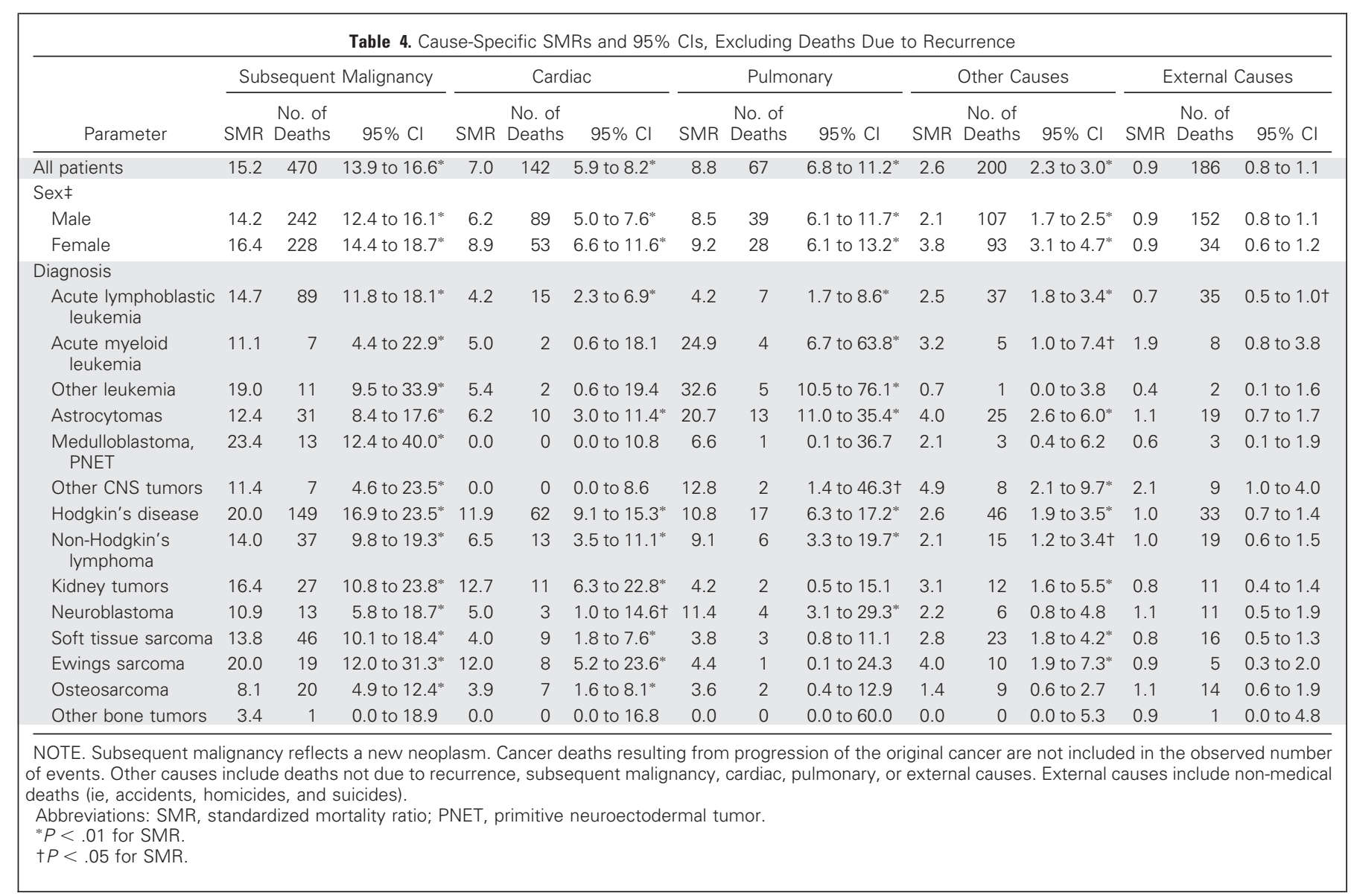

in durable remissions, but this may be at the cost of an increase in late treatment-related death due to more intense, multimodal therapeutic regimens. Unfortunately, however, this analysis was limited by its absence of information regarding specific treatments and was unable to estimate the risks of specific causes of death in relation to type of treatment received.

A single institution study from St Jude Children's Research Hospital that included 2,053 5-year survivors also documented an improvement in long-term mortality across treatment eras (patients diagnosed 1962 to 1970 compared to those diagnosed 1971 to 1983). In addition to a reduction in the cumulative incidence of death at 20 years $(23.6 \% v 13.4 \% ; P<.0001)$, the cumulative incidence of death from recurrence at 20 years improved as well $(17.6 \% v 6.7 \%$; $P<$ $.0001)$. The incidence of death from second malignancies increased $(1.7 \%$ v $3.7 \%)$, but this did not reach statistical significance, emphasizing the important need for larger studies that have the power to determine differences for such important evaluations. While a number of other small, institutionally based studies and late mortality studies of specific diagnostic groups exist, none approach the size of the CCSS population. ${ }^{20-33}$

One important exception, however, is a population-based study from five Nordic countries (Denmark, Finland, Iceland, Norway, and Sweden) that identified 13,711 survivors diagnosed between 1960 and 1989 before the age of $20 .{ }^{34}$ Many of their findings confirm what the CCSS has identified among survivors in the United States including an overall SMR of 10.8, overall mortality at 25 years of 14\%, and higher absolute mortality rates in males (Table 6). The CCSS, as an institutionally based study, may be at risk of not representing the broader population of childhood cancer survivors (poor generalizability), however, such strong correlation of findings with a population-based study suggests this is not the case. In addition, however, the Nordic study also reported only $7.1 \%$ of their population deceased due to subsequent malignancy for an SMR of 4.9, very much lower than that reported by the CCSS (SMR, 15.2). Possible explanations for this discrepancy include inclusion of patients from the 10-year period before 1970 that were not included in the CCSS study as these patients may have lower rates of SMN. In addition, due to the rules of the official mortality statistics as applied the Nordic countries, this study is at risk for misclassification of outcome by overestimating death attributable to primary disease and underestimating death attributable to subsequent neoplasms and treatment-related death.

\section{CONCLUSION}

For children diagnosed with pediatric malignancies, 5-year survival has served not only as a benchmark for survival but as a goal for patients and families alike. However, significant risk for late mortality is now well-established, with higher risk for late recurrence in the early decades followed by increasing rates of subsequent malignancy and treatment-related deaths in later decades. Additional associations with sex, primary diagnosis, and therapeutic modalities should now inform 


\begin{tabular}{|c|c|c|c|c|c|c|}
\hline \multirow[b]{2}{*}{ Independent Risk Factor } & \multicolumn{2}{|c|}{ Subsequent Malignancy } & \multicolumn{2}{|c|}{ Cardiac } & \multicolumn{2}{|c|}{ Other Causes } \\
\hline & $\mathrm{RR}$ & $95 \% \mathrm{Cl}$ & $\mathrm{RR}$ & $95 \% \mathrm{Cl}$ & $\mathrm{RR}$ & $95 \% \mathrm{Cl}$ \\
\hline \multicolumn{7}{|l|}{ Sex } \\
\hline Male & 1.0 & & 1.0 & & 1.0 & \\
\hline Female & 1.3 & 1.1 to $1.5^{*}$ & 1.4 & 1.0 to $1.9 \dagger$ & 1.9 & 1.5 to $2.4^{*}$ \\
\hline \multicolumn{7}{|l|}{ Age at diagnosis, years } \\
\hline $0-4$ & 1.5 & 1.1 to $1.9^{*}$ & 2.1 & 1.3 to $3.6^{*}$ & 1.3 & 0.9 to 1.9 \\
\hline $5-9$ & 1.1 & 0.8 to 1.4 & 1.4 & 0.9 to 2.3 & 1.5 & 1.1 to $2.2 \dagger$ \\
\hline $10-14$ & 0.9 & 0.7 to 1.2 & 0.8 & 0.5 to 1.3 & 1.1 & 0.8 to 1.6 \\
\hline $15-20$ & 1.0 & & 1.0 & & 1.0 & \\
\hline \multicolumn{7}{|l|}{ Years of diagnosis } \\
\hline 1970-1973 & 1.3 & 1.0 to 1.8 & 1.7 & 0.9 to 3.4 & 1.2 & 0.7 to 1.8 \\
\hline 1974-1977 & 1.1 & 0.8 to 1.4 & 2.1 & 1.2 to $3.7 \dagger$ & 0.9 & 0.6 to 1.3 \\
\hline $1978-1981$ & 0.8 & 0.6 to 1.1 & 1.8 & 1.0 to 3.1 & 0.8 & 0.5 to 1.2 \\
\hline 1982-1986 & 1.0 & & 1.0 & & 1.0 & \\
\hline \multicolumn{7}{|l|}{ Years since diagnosis } \\
\hline $5-9$ & 2.7 & 2.1 to $3.5^{*}$ & 2.2 & 1.3 to $3.6^{*}$ & 1.6 & 1.1 to $2.3+$ \\
\hline $10-14$ & 1.9 & 1.5 to $2.5^{*}$ & 1.7 & 1.0 to $2.7 \dagger$ & 1.4 & 1.0 to 2.0 \\
\hline $15-19$ & 1.4 & 1.1 to $1.8 \dagger$ & 1.5 & 1.0 to $2.3+$ & 0.9 & 0.6 to 1.3 \\
\hline $20+$ & 1.0 & & 1.0 & & 1.0 & \\
\hline \multicolumn{7}{|l|}{ Radiation $\neq$} \\
\hline Yes & 2.9 & 2.1 to $4.2^{*}$ & 3.3 & 2.0 to $5.5^{*}$ & 2.0 & 1.3 to $3.1^{*}$ \\
\hline No & 1.0 & & 1.0 & & 1.0 & \\
\hline \multicolumn{7}{|l|}{ Alkylating agent score } \\
\hline Not exposed & 1.0 & & 1.0 & & 1.0 & \\
\hline $1-2$ & 1.4 & 1.0 to $2.0 \dagger$ & 0.6 & 0.3 to 1.2 & 1.0 & 0.7 to 1.7 \\
\hline $3-4$ & 1.8 & 1.1 to $2.8 \dagger$ & 0.6 & 0.3 to 1.4 & 1.2 & 0.8 to 1.9 \\
\hline $5+$ & 2.2 & 1.6 to $3.0^{*}$ & 1.7 & 1.0 to 3.0 & 1.7 & 1.0 to $2.9+$ \\
\hline \multicolumn{7}{|l|}{ Anthracycline, mg/m² } \\
\hline Not exposed & 1.0 & & 1.0 & & 1.0 & \\
\hline $1-100$ & 1.1 & 0.5 to 2.1 & 2.5 & 0.7 to 9.2 & 1.7 & 0.7 to 4.1 \\
\hline $101-250$ & 1.1 & 0.6 to 1.9 & 2.3 & 0.9 to 6.0 & 1.6 & 0.9 to 3.1 \\
\hline $251-400$ & 1.2 & 0.8 to 1.7 & 2.2 & 1.3 to $4.0^{*}$ & 1.4 & 0.9 to 2.2 \\
\hline $401+$ & 1.4 & 0.9 to 2.1 & 3.1 & 1.6 to $5.8^{*}$ & 1.7 & 0.9 to 3.0 \\
\hline \multicolumn{7}{|l|}{ Epipodophyllotoxin, mg/m² } \\
\hline Not exposed & 1.0 & & 1.0 & & 1.0 & \\
\hline $1-982$ & 1.1 & 0.4 to 2.7 & 0.7 & 0.1 to 5.1 & 1.2 & 0.3 to 4.5 \\
\hline $983-4,108$ & 1.6 & 0.6 to 4.0 & 0.8 & 0.1 to 6.0 & 0.9 & 0.2 to 3.8 \\
\hline $4,109+$ & 2.3 & 1.2 to $4.5 \dagger$ & 1.9 & 0.4 to 8.5 & 0.8 & 0.2 to 3.9 \\
\hline \multicolumn{7}{|l|}{ Bleomycin, mg/m² } \\
\hline Not exposed & 1.0 & & 1.0 & & 1.0 & \\
\hline $1-59$ & 1.2 & 0.7 to 2.1 & 1.7 & 0.8 to 3.9 & 0.8 & 0.3 to 2.3 \\
\hline $60-119$ & 1.2 & 0.5 to 2.7 & 0.9 & 0.3 to 2.8 & 1.0 & 0.3 to 3.0 \\
\hline $119+$ & 1.9 & 0.8 to 4.5 & 1.3 & 0.3 to 5.7 & 0.6 & 0.1 to 3.3 \\
\hline
\end{tabular}

future treatment regimens in an attempt to minimize long-term treatment related mortality while maintaining durable remissions. The CCSS investigations of late mortality provide the largest published population assessed to date with detailed treatment information, allowing assessment of potential associations between therapeutic modalities and late-mortality that could not be examined previously. Limitations include the absence of patients with retinoblastoma and the inability to draw conclusions regarding the genetic associations that may predispose to subsequent neoplasms. However, the ongoing, prospective follow-up of this population as they age into their fourth and fifth decades of life will serve as an essential early warning system for the detection of new trends and developments in late mortality. In addition, with the CCSS expansion to include survivors diagnosed between 1987 and 1999, it will be possible to determine whether our most modern primary therapies are improving 5-year survival, as well as producing durable, long-term remissions, with minimal risk for treatment-related mortality.

Beyond continued observation of the mortality experience of this unique cohort, the CCSS will be able to provide new information regarding the potential role of health-related behaviors on late 


\begin{tabular}{|c|c|c|c|c|}
\hline \multirow[b]{2}{*}{ Parameter } & \multicolumn{2}{|c|}{ Childhood Cancer Survivor Study ${ }^{6}$} & \multicolumn{2}{|c|}{ Nordic Study ${ }^{34}$} \\
\hline & No. & $\%$ & No. & $\%$ \\
\hline Country & \multicolumn{2}{|c|}{ United States } & \multicolumn{2}{|c|}{$\begin{array}{l}\text { Denmark, Finland, Norway, Iceland, } \\
\text { Sweden }\end{array}$} \\
\hline Type of study & \multicolumn{2}{|c|}{ Hospital based } & \multicolumn{2}{|c|}{ Population based } \\
\hline Age at diagnosis & \multicolumn{2}{|c|}{$<21$} & \multicolumn{2}{|c|}{$<20$} \\
\hline Years of diagnosis & \multicolumn{2}{|c|}{ 1970-1986 } & \multicolumn{2}{|c|}{ 1960-1989 } \\
\hline No. of 5-year survivors & \multicolumn{2}{|c|}{20,227} & \multicolumn{2}{|c|}{13,711} \\
\hline Alive & 18,197 & 90.0 & 12,289 & 89.6 \\
\hline Dead & 2,030 & 10.0 & 1,422 & 10.4 \\
\hline Death due to recurrent tumor & 1,246 & 67.4 & 976 & 69.6 \\
\hline Death due to second cancer & 235 & 12.7 & 99 & 7.1 \\
\hline Noncancer treatment-related deaths & 159 & 7.8 & 160 & 11.3 \\
\hline Unrelated deaths & 208 & 10.2 & 167 & 11.9 \\
\hline Standardized mortality ratio & \multicolumn{2}{|c|}{10.8} & \multicolumn{2}{|c|}{10.8} \\
\hline
\end{tabular}

mortality. Health behaviors such as tobacco use, alcohol consumption, diet, exercise, and health screening practices all influence mortality among the general population. It is likely that all or some of these health behaviors may have a greater impact on the mortality experience of adult survivors of childhood cancer. It is only through continued follow-up and characterization of this survivor population that it will be possible to identify and quantify the influence of the multitude of factors that will determine their ultimate longevity.

\section{AUTHORS' DISCLOSURES OF POTENTIAL CONFLICTS} OF INTEREST

The author(s) indicated no potential conflicts of interest.

\section{AUTHOR CONTRIBUTIONS}

Manuscript writing: Gregory T. Armstrong, Qi Liu, Yutaka Yasui, Joseph P. Neglia, Wendy Leisenring, Leslie L. Robison, Ann C. Mertens

\section{REFERENGES}

1. Hewitt M, Weiner SL, Simone JV (eds): Childhood Cancer Survivorship: Improving Care and Quality of Life. Washington, DC, National Academies Press, 2003

2. Ries LA, Harkins D, Krapcho $M$, et al: SEER Cancer Statistics Review, 1975-2003. Bethesda, MD, National Cancer Institute, 2006

3. Li FP, Cassady JR, Jaffe N: Risk of second tumors in survivors of childhood cancer. Cancer 35:1230-1235, 1975

4. Hawkins MM, Kingston JE, Kinnier Wilson LM: Late deaths after treatment for childhood cancer. Arch Dis Child 65:1356-1363, 1990

5. Nicholson HS, Fears TR, Byrne J: Death during adulthood in survivors of childhood and adolescent cancer. Cancer 73:3094-3102, 1994

6. Mertens AC, Yasui Y, Neglia JP, et al: Late mortality experience in five-year survivors of childhood and adolescent cancer: The Childhood Cancer Survivor Study. J Clin Oncol 19:3163-3172, 2001

7. Reference deleted

8. Mertens AC, Liu Q, Neglia JP, et al: Causespecific late mortality among 5-year survivors of childhood cancer: The Childhood Cancer Survivor Study. J Natl Cancer Inst 100:1368-1379, 2008

9. Reaman G, Zeltzer P, Bleyer WA, et al: Acute lymphoblastic leukemia in infants less than one year of age: A cumulative experience of the Children's Cancer Study Group. J Clin Oncol 3:1513-1521, 1985

10. Duffner PK, Horowitz ME, Krischer JP, et al: Postoperative chemotherapy and delayed radiation in children less than three years of age with malignant brain tumors. N Engl J Med 328:1725-1731, 1993

11. Armstrong GT, Sklar CA, Hudson MM, et al: Long-term health status among survivors of childhood cancer: Does sex matter? J Clin Oncol 25: 4477-4489, 2007

12. Neglia JP, Friedman DL, Yasui Y, et al: Second malignant neoplasms in five-year survivors of childhood cancer: Childhood cancer survivor study. J Natl Cancer Inst 93:618-629, 2001

13. Bhatia $S$, Yasui $Y$, Robison $L L$, et al: High risk of subsequent neoplasms continues with extended follow-up of childhood Hodgkin's disease: Report from the Late Effects Study Group. J Clin Oncol 21:4386-4394, 2003

14. Silber JH, Jakacki RI, Larsen RL, et al: Increased risk of cardiac dysfunction after anthracyclines in girls. Med Pediatr Oncol 21:477-479, 1993

15. Lipshultz SE, Lipsitz SR, Mone SM, et al: Female sex and drug dose as risk factors for late cardiotoxic effects of doxorubicin therapy for childhood cancer. N Engl J Med 332:1738-1743, 1995

16. Didi $M$, Didcock E, Davies HA, et al: High incidence of obesity in young adults after treatment of acute lymphoblastic leukemia in childhood. $\mathrm{J} \mathrm{Pe}$ diatr 127:63-67, 1995

17. Odame I, Reilly JJ, Gibson BE, et al: Patterns of obesity in boys and girls after treatment for acute lymphoblastic leukaemia. Arch Dis Child 71:147149,1994

18. Oeffinger $K C$, Mertens $A C$, Sklar $C A$, et al: Obesity in adult survivors of childhood acute lymphoblastic leukemia: A report from the Childhood
Cancer Survivor Study. J Clin Oncol 21:1359-1365, 2003

19. Robertson CM, Hawkins MM, Kingston JE: Late deaths and survival after childhood cancer: Implications for cure. Bmj 309:162-166, 1994

20. Cardous-Ubbink MC, Heinen RC, Langeveld $\mathrm{NE}$, et al: Long-term cause-specific mortality among five-year survivors of childhood cancer. Pediatr Blood Cancer 42:563-573, 2004

21. Dama E, Pastore G, Mosso ML, et al: Late deaths among five-year survivors of childhood cancer: A population-based study in Piedmont Region, Italy. Haematologica 91:1084-1091, 2006

22. MacArthur AC, Spinelli JJ, Rogers PC, et al: Mortality among 5 -year survivors of cancer diagnosed during childhood or adolescence in British Columbia, Canada. Pediatr Blood Cancer 48:460467, 2007

23. Eng C, Li FP, Abramson DH, et al: Mortality from second tumors among long-term survivors of retinoblastoma. J Natl Cancer Inst 85:1121-1128, 1993

24. Cotterill SJ, Pearson AD, Pritchard J, et al: Late relapse and prognosis for neuroblastoma patients surviving 5 years or more: A report from the European Neuroblastoma Study Group "Survey". Med Pediatr Oncol 36:235-238, 2001

25. Bhatia S, Francisco L, Carter A, et al: Late mortality after allogeneic hematopoietic cell transplantation and functional status of long-term survivors: Report from the Bone Marrow Transplant Survivor Study. Blood 110:3784-3792, 2007

26. Bhatia S, Robison LL, Francisco L, et al: Late mortality in survivors of autologous hematopoieticcell transplantation: Report from the Bone Marrow Transplant Survivor Study. Blood 105:4215-4222, 2005 
27. Green DM, Hyland A, Chung CS, et al: Cancer and cardiac mortality among 15-year survivors of cancer diagnosed during childhood or adolescence. $\mathrm{J}$ Clin Oncol 17:3207-3215, 1999

28. Lawless SC, Verma P, Green DM, et al: Mortality experiences among $15+$ year survivors of childhood and adolescent cancers. Pediatr Blood Cancer 48:333-338, 2007

29. Morris EB, Gajjar A, Okuma JO, et al: Survival and late mortality in long-term survivors of pediatric CNS tumors. J Clin Oncol 25:1532-1538, 2007
30. Pui $\mathrm{CH}$, Cheng $\mathrm{C}$, Leung $W$, et al: Extended follow-up of long-term survivors of childhood acute lymphoblastic leukemia. N Engl J Med 349:640-649, 2003

31. Bluhm EC, Ronckers C, Hayashi RJ, et al: Cause-specific mortality and second cancer incidence after non-Hodgkin lymphoma: A report from the Childhood Cancer Survivor Study. Blood 111: 4014-4021, 2008

32. Mody R, Li S, Dover DC, et al: Twenty-fiveyear follow-up among survivors of childhood acute lymphoblastic leukemia: A report from the Child- hood Cancer Survivor Study. Blood 111:5515-5523, 2008

33. Mulrooney DA, Dover DC, Li S, et al: Twenty years of follow-up among survivors of childhood and young adult acute myeloid leukemia: A report from the Childhood Cancer Survivor Study. Cancer 112: 2071-2079, 2008

34. Moller TR, Garwicz S, Barlow L, et al: Decreasing late mortality among five-year survivors of cancer in childhood and adolescence: A populationbased study in the Nordic countries. J Clin Oncol 19:3173-3181, 2001 